DOI: $10.5216 /$ racs.v6.67284

\title{
Por que documentar e descrever línguas? A importância desses estudos para revitalização e fortalecimento de línguas indígenas brasileiras
}

\author{
Beatriz Furlan Toledo ${ }^{1}$ \\ Camille Cardoso Miranda ${ }^{2}$
}

\section{RESUMO}

Os estudos de documentação e descrição linguística são dois passos importantes para o fortalecimento, manutenção, preservação e revitalização de línguas, principalmente, daquelas que estão em ameaça, como é o caso de muitas línguas indígenas brasileiras. A tarefa de registrar uma língua compromete duas atividades básicas que se relacionam entre si, mas que têm objetivos diferentes: a documentação e a descrição linguística. $\mathrm{O}$ artigo apresenta algumas reflexões acerca da importância dos estudos de documentação e descrição para o fortalecimento e revitalização de línguas ameaçadas. São apresentados e discutidos exemplos de ações de valorização e revitalização de quatro línguas indígenas brasileiras (Kaingang, Nhandewa-Guarani, Xokleng/Laklãnõ e Krenak) com o objetivo de promover a valorização linguística e cultural dessas línguas, além de reafirmar a importância desses estudos para o conhecimento científico e de fenômenos linguísticos de línguas indígenas brasileiras.

PALAVRAS-CHAVE: Documentação \& Descrição. Revitalização. Línguas Indígenas.

\section{Why document and describe languages? The importance of these studies in the policy of revitalization and strengthening of Brazilian indigenous languages}

\begin{abstract}
Studies of documentation and linguistic description are two important steps in the strengthening, maintenance, preservation and revitalization of languages, especially those that are under endangered, as is the case of many Brazilian indigenous languages. The task of recording a language involves two basic activities that are related but have different objectives: documentation and linguistic description. This paper presents some reflections on the importance of documentation and description studies for strengthening and revitalizing endangered languages. Besides that, examples of revitalization actions for four Brazilian languages (Kaingang, Nhandewa-Guarani, Xokleng/Laklãnõ and Krenak) are presented in order to discuss and promote the valorization linguistic and cultural of these languages, in addition to reaffirming the importance of these studies for scientific knowledge and linguistic phenomena of Brazilian indigenous languages.
\end{abstract}

\footnotetext{
1 Universidade Estadual de Campinas (UNICAMP), Campinas, São Paulo, Brasil. E-mail: bfurlantoledo@gmail.com.

2 Universidade Estadual de Campinas (UNICAMP), Campinas, São Paulo, Brasil. E-mail: camiranda126@gmail.com.
} 
KEYWORDS: Documentation \& Description. Revitalization. Indigenous Languages.

\section{Introdução}

Sabemos que as línguas são objetos fugidios que mudam ou desaparecem com muita facilidade por diferentes fatores: incorporação de outras línguas majoritárias, a falta de transmissão às futuras gerações, questões de pressões políticas e sociais. De acordo com Austin \& Sallabank (2011, p. 01), existem cerca de sete mil línguas faladas no mundo, contudo, pelo menos a metade delas podem não existir no futuro, uma vez que gerações mais novas não as estão aprendendo.

O Brasil é um país que se caracteriza por sua considerável diversidade sociocultural e linguística dentre os países da América do Sul, sendo, por isso, uma nação multilíngue. Antigamente, o número de línguas originárias que eram faladas à chegada dos europeus era de aproximadamente 1.175 línguas indígenas, no início da colonização (RODRIGUES, 1993). Segundo Rodrigues, "houve, portanto, uma redução drástica, por extinção, de $85 \%$ ou mais, na diversidade indígena do Brasil, a qual corresponde, quase diretamente, à redução dos próprios povos indígenas" (1993, p. 99). Atualmente, o Brasil apresenta um número bastante reduzido de línguas indígenas. De acordo com Galucio et al (2018), existe um número de 150 línguas indígenas brasileiras, sendo essa redução um processo preocupante, violento e ainda bastante presente.

Conforme Austin \& Sallabank (2011, p.1), as línguas ameaçadas estão apresentando mudanças nos seus perfis, pois muitas delas são apenas faladas por pessoas mais velhas e os jovens tipicamente estão apresentando um processo de mudança linguística que influencia negativamente o fortalecimento dessas línguas. Desse modo, no caso do Brasil, muitos povos indígenas estão usando cada vez mais o português em detrimento de sua própria língua indígena, o que pode levar à extinção das línguas. De acordo com Galucio et al (2018), no Brasil, nos últimos dois séculos, o português tem ocupado um status tão elevado que uma grande parte da população pensa que o Brasil é um país monolíngue. Assim, observando este cenário, é importante refletir sobres algumas questões:

1. Por que documentar e descrever línguas?

2. Qual a importância desses estudos para o fortalecimento e revitalização de línguas minorizadas? 
3. Quais os programas de documentação que auxiliam na preservação desses idiomas?

4. Qual o papel essencial da revitalização linguística?

Essas e outras reflexões que serão discutidas nesse trabalho são passos importantes para pensar questões de fortalecimento linguístico e processos de revitalização de línguas indígenas brasileiras. Nesse sentido, o artigo tem como objetivo descrever algumas etapas importantes da documentação e descrição para a revitalização de línguas indígenas brasileiras. Assim, a tarefa de registrar uma língua pouco conhecida compromete-se em duas atividades: a primeira sendo a documentação linguística e a segunda sendo a descrição, ambas estão relacionadas, mas seus objetivos são diferentes, já que a primeira objetiva registrar práticas linguísticas e tradições culturais de uma comunidade da fala, enquanto a segunda objetiva o registro de uma língua como um sistema abstrato (cf. HIMMELMANN, 1998).

Sendo assim, entendemos que esses estudos se tornam essenciais para o fortalecimento e práticas de revitalização de uma língua, além de fornecer conhecimentos científicos e linguísticos para a sociedade de um modo geral. Como exemplo de uma prática de fortalecimento e políticas linguísticas, apresentamos também algumas ações de valorização e revitalização relacionadas à quatro línguas indígenas (Kaingang, Nhandewa-Guarani, Xokleng/Laklãnõ e Krenak) para discutir questões de políticas linguísticas que buscam promover a valorização das línguas e culturas indígenas do Brasil.

O artigo está organizado em quatro seções, além desta introdução. Na primeira, apresenta-se uma visão geral acerca das línguas indígenas brasileiras; na segunda, discute-se sobre a importância da documentação e descrição para a preservação de línguas ameaçadas; na terceira, são apresentados modos de revitalização linguística e cultural; na quarta apresentam-se exemplos de ações de valorização e revitalização linguística no meio digital e, por fim, são feitas algumas considerações gerais sobre a relevância e contribuição de trabalhos de descrição e documentação para a revitalização linguística.

\section{Situação das línguas indígenas brasileiras: panorama histórico e atual}

Sabe-se que quando os portugueses chegaram ao Brasil se depararam com a existência de povos nativos, com suas línguas, costumes e culturas. De acordo com Seki (2000), o primeiro contato ocorreu com povos Tupi que ocupavam, na época, toda parte da costa brasileira. Rodrigues (1986) afirma que o território brasileiro abrigava cerca de 1.175 línguas 
indígenas, mas esse número foi reduzindo drasticamente, resultando na perda de aproximadamente mil línguas.

Atualmente, ainda não se sabe o número exato de línguas indígenas faladas no Brasil, devido às dificuldades inerentes de acesso às comunidades indígenas existentes ou por questões de inteligibilidade mútua, que se dá quando falantes de duas variedades linguísticas podem compreender um ao outro, fazendo com que a variedade seja considerada mutuamente compreensível. Caso isso aconteça, pode-se considerar variedade de uma mesma língua. Contudo, a inteligibilidade mútua é até um certo ponto uma atitude política, uma vez que entra na questão de identidade, de pertencimento e resistência de uma determinada comunidade da fala, ao não considerar a língua como variedade.

De acordo com Moore \& Galucio (2016, p. 44), a noção de inteligibilidade mútua, apesar de seus problemas, tem a virtude de oferecer um critério consistente e razoavelmente objetivo para agrupar variantes em idiomas. Por esse critério, os autores explicam que talvez o número não ultrapasse 153 línguas (MOORE \& GALUCIO, 2016, p.44). Já Rodrigues (2005) registra 199 línguas indígenas, mas esse número é impreciso, porque também é um dado antigo. De acordo com os últimos dados do Instituto Brasileiro de Geografia e Estatística - IBGE $(2010)^{3}$, a população indígena é de aproximadamente 897 mil pessoas, compondo 305 etnias. De acordo com o IBGE são faladas cerca de 274 línguas, por aproximadamente 37,4\% do total de indígenas. D'Angelis (2019) refuta esse dado, alegando que nesse censo não houve um critério adequado para definir as diferenças de dialetos, classificação de línguas, línguas isoladas etc. Assim como Moore \& Galucio (2016), D’Angelis (2019, p.23) acredita que o número não ultrapassaria a existência de 150 línguas. A divergência em relação ao número de línguas existentes se dá pelo fato de que uma língua não é definida somente por critérios linguísticos, mas também, por critérios políticos e identitários.

Dados sobre a transmissão das línguas são ainda mais difíceis de conseguir, embora seja a principal fonte de futuro de uma língua. Moore e Galucio (2016, p. 45) afirmam que um dos parâmetros principais na avaliação da situação de um idioma é o número de pessoas que o falam. Assim “o grau de ameaça às línguas indígenas foi gravemente subestimado por anos no Brasil devido à confusão entre o número de falantes e a população de grupo, e o problema ainda continua" (MOORE \& GALUCIO, 2016, p. 45). Moore et al (2008) estimam que pelo menos $21 \%$ das aproximadamente 150 línguas indígenas do Brasil estão ameaçadas de

\footnotetext{
${ }^{3}$ Disponível em: https://censo2010.ibge.gov.br/noticias-censo?busca=1\&id=3\&idnoticia=2194\&t=censo-2010poblacao-indigena-896-9-mil-tem-305-etnias-fala-274\&view=noticia
} 
extinção em um futuro próximo por conta do baixo número de falantes e falta de transmissão. Assim, estudos científicos, antropológicos, educacionais e registros dessas línguas, bem como, políticas afirmativas que visam ao fortalecimento dessas línguas necessitam cada vez mais serem realizados.

Conforme Moore et al (2008, p. 40), a situação torna-se cada vez mais preocupante, se levarmos em conta que línguas mais ameaçadas são também aquelas que têm menos chances de serem conhecidas pela ciência. Segundo os autores, apesar do avanço linguístico nos estudos de línguas indígenas nas últimas décadas, levantamentos revelam que essas línguas são conhecidas apenas em parte e que sobre a maioria há pouco ou nenhum estudo. Assim, Moore et al (2008, p.40) estimam que

- $12 \%$ têm descrição completa;

- $33 \%$ têm descrição avançada;

- $32 \%$ têm descrição ainda incipiente;

- $23 \%$ têm pouca ou nenhuma descrição científica significativa.

Esse panorama foi realizado em 2008 e, com certeza, esses números devem ter mudado, por isso, é muito difícil delimitar o número exato do avanço das pesquisas realizadas até o momento. No mais, acreditamos que ainda existe a necessidade de que mais estudos científicos e descrições avançadas dessas línguas sejam feitos, mesmo aquelas que contam com poucos falantes, já que todas as línguas têm valor científico (MOORE ET AL, 2008, p. 40).

Consequentemente, o desaparecimento de uma língua é uma perda para o patrimônio intelectual e cultural da humanidade. De acordo com Galucio et al (2018), as línguas indígenas, no passado, desapareceram sem qualquer registro e várias línguas atualmente faladas ou lembradas correm o perigo de um destino semelhante. Nesse sentido, trabalhos de descrição, documentação e revitalização de línguas minorizadas são de suma importância não apenas para a ampliação de estudos linguísticos, mas também, para a preservação de saberes socioculturais e de estruturas linguísticas que estão se perdendo, devido ao processo de obsolescência que muitas línguas indígenas brasileiras vêm passando.

No que diz respeito à classificação linguística das línguas brasileiras, elas são divididas conforme a relação de parentesco, a partir de um estudo histórico-comparativo. Essas línguas são agrupadas em dois grandes troncos linguísticos (Macro Jê e Tupi), em famílias (Aruák, Karib, Pano, Tukano, Arawá, Katarina, Nadahup (Maku), Nambikwara, 
Txapakúra, Yanomani, Bóra, Guaikurú e Múra), existem também sete línguas isoladas ${ }^{4}$ (Aikanã, Kanoê, Kwazá, Irântxe, Mynký, Trumai e Tikuna), além de pidgins e línguas crioulas ${ }^{5}$ faladas no Norte do Brasil, na fronteira com Amapá e Guiana Francesa (Galibí Marworno (Galibí de Uaçá) e o Karipuna do Norte (Karipuna do Amapá)). Atualmente, a maioria dessas línguas é falada no norte do país e está altamente ameaçada.

Em 2002 e 2003, a UNESCO solicitou a um grupo internacional de linguistas que desenvolvesse uma estrutura para determinar a vitalidade de uma língua, a fim de auxiliar no desenvolvimento de políticas, identificação de necessidades e medidas apropriadas de preservação das línguas do mundo. O grupo de especialistas, sobre línguas em perigo de extinção, elaborou um documento conceitual de referência intitulado "Language Vitality and Endangerment", que estabeleceu os seguintes nove critérios:

1. Número absoluto de falantes;

2. Transmissão geracional da língua;

3. Atitude dos membros da comunidade em relação a própria língua;

4. Mudanças nos domínios de uso da língua;

5. Ações e políticas governamentais em relação à língua, incluindo políticas de status e uso oficiais;

6. Tipo e qualidade da documentação linguística;

7. Respostas a novos domínios e mídias;

8. Disponibilidade de materiais para aprendizagem e ensino da língua e literaturas na língua;

9. Proporção de falantes entre a população total do território.

A UNESCO ressalta que nenhum fator isolado é suficiente para avaliar o estágio em que se encontra a língua de uma comunidade, no entanto, em conjunto, esses nove fatores podem determinar a viabilidade de uma língua, sua função na sociedade e o tipo de medidas necessárias para sua manutenção ou revitalização. Tendo em vista esses critérios, a UNESCO classifica as línguas em seis níveis progressivos: segura, vulnerável, definitivamente em perigo, severamente em perigo, criticamente em perigo e extinta. Além disso, o "Atlas

\footnotetext{
${ }^{4}$ Línguas isoladas são aquelas que pelo estudo comparativo não podem se enquadrar em nenhuma das famílias linguísticas, seja por conta de discrepâncias gramaticais ou por conter pouco ou nenhum dado que possa inserilas em uma determinada família ou tronco linguístico.

${ }^{5}$ Rodrigues $(2019$, p. 44$)$ define pidgin como "um tipo de língua reduzida, resultante do extenso contato entre dois ou mais povos aloglotas". Conforme Hall (1962), um pidgin surge quando uma situação de emergência exige comunicação num nível mínimo de compreensão e, passado algum tempo, ele pode se tornar uma língua da comunidade, passando a ser chamado e definido como "língua crioula".
} 
Interativo de Línguas do Mundo em Perigo" apresenta as línguas que se encontram revitalizadas. Muitas comunidades indígenas brasileiras contam com pouquíssimos falantes, sendo que 33 povos possuem apenas de 1 a 10 falantes em suas comunidades (UNESCO, 2019). Há, ainda, 45 línguas em situação crítica de perigo (criticamente em perigo), ou seja, apenas a um nível da situação de extinção. De acordo com o Atlas da UNESCO, nenhuma língua brasileira está classificada como "revitalizada", até o momento.

O processo de perda de uma língua ocorre sem que seus membros possam decidir sobre tais perdas. Inicialmente a perda linguística se dá, principalmente, devido ao desaparecimento físico dos falantes, em decorrência de epidemias, extermínio direto, escravização, redução de territórios, destruição das condições de sobrevivência e aculturação forçada (SEKI, 2000). Posteriormente, a extinção de línguas indígenas deve muito a políticas centralizadoras portuguesas e depois brasileiras, pois mesmo após a independência do Brasil, a sobrevivência de outras línguas dentro do território nacional continuou sendo ameaçada. D’Angelis (2002) explica alguns dos fatores que implicam na perda linguística, ressaltando como essa perda tem um forte viés político:

\footnotetext{
Por outro lado, o abandono da língua materna pode ser provocado por certas razões, digamos, "práticas". Quanto mais a pessoa ou grupo é chamado a interagir com os "brancos" na língua portuguesa (pelo comércio, pelas necessidades de trabalho, pelas questões políticas, pela pressão da escola, pela pressão das religiões estrangeiras, etc), menos espaço deixa para uso da própria língua. Se isso se generaliza para todos os tipos de falantes (adultos de ambos os sexos, velhos e até crianças), em pouco tempo as interações dentro da própria comunidade passam a ser feitas na língua dos invasores, começando nos lugares e situações mais relacionados com a sociedade dominante: no Posto Indígena (com funcionários do governo), na escola (em geral, com material didático em língua portuguesa, e muito frequentemente, com professores "brancos", ou índios que não falam a língua indígena), nas igrejas das religiões dos não-índios, etc (D’ANGELIS, 2002, p. 111).
}

O poder econômico, cultural e militar das comunidades falantes define bem o status de cada língua (CRYSTAL, 2005). Como a língua portuguesa, no Brasil, possui muito mais poder econômico, principalmente, ao oferecer condições de renda para muitas comunidades, acesso a bens e serviços e mais poder militar, ocasiona em muitas línguas indígenas o desconhecimento, pois não há divulgação, e nem mesmo é dada alguma importância à informação de que o Brasil é multilíngue, que possui mais de uma centena de outras línguas, além do português. Além disso, é desconhecido por grande parte da população brasileira que alguns municípios brasileiros cooficializaram, por meio de leis, outras línguas como o Nheengatu, Tukano, Baniwa e recentemente a língua Yanomami no município de São Gabriel da Cachoeira, no Amazonas. 
Assim sendo, percebemos que há muito o que fazer nos estudos relacionados às línguas indígenas brasileiras. Moore \& Galucio (2016, p.46) explicam que a documentação linguística, projetos e descrição não dão certeza de uma estimativa real dos registros realizados sobre essas línguas e comunidades, o mesmo ocorre com os projetos de revitalização já que também são bastante difíceis de estimar. Desse modo, é importante cada vez mais refletir sobre a importância de levantar esses dados, como também, realizar trabalhos de descrição, documentação e revitalização de línguas minorizadas. Enfatizamos que são estudos fundamentais, não apenas para a ampliação de estudos linguísticos, mas para fortalecer políticas linguísticas de idiomas que estão em processo de extinção. A seção que segue esboça alguns pontos fundamentais da documentação e descrição linguística, além de elencar programas de documentação que ajudam no fortalecimento e revitalização de línguas minoritárias.

\section{Por que documentar e descrever línguas? A importância desses estudos para o fortalecimento e revitalização de línguas minoritárias}

Como dito anteriormente, as línguas são objetos que mudam ou desaparecem em um tempo muito rápido, ocasionando uma perda linguística gigantesca para a comunidade científica, para a humanidade em geral e, principalmente, para a comunidade de fala. Desse modo, questiona-se o papel da documentação e descrição de uma língua em perigo de extinção. Essa seção busca refletir sobre a importância desses estudos na linguística, a definição e a diferença que ambos os estudos têm, além de mostrar alguns programas de documentação linguística que visam ao fortalecimento de línguas indígenas brasileiras.

\subsection{O que é a documentação linguística?}

De acordo com Himmelman (1998), o conceito de documentação linguística, como campo de pesquisa linguística e atividade, procede como uma base dos pressupostos de práticas linguísticas e tradições em uma dada comunidade de fala, além de documentar aspectos culturais de uma determinada cultura. Para o autor, o objetivo de documentar línguas é fornecer um registro compreensível das características das práticas linguísticas de uma comunidade de fala. Ainda para o autor (1998), as práticas linguísticas e tradição são manifestadas em duas formas: (1) uma observação linguística na interação do dia a dia entre os membros da comunidade e (2) conhecimentos metalinguísticos de falantes nativos, 
manifestados na sua habilidade de fornecer interpretações e sistematizações para unidades linguísticas e eventos. Conforme Woodbury (2011, p.159), a documentação linguística tem como objetivo "a criação, anotação, preservação e divulgação de registros transparentes de uma língua", configurando-se como um processo que deve ser acelerado, ampliado, popularizado e transformado (WOODBURY, 2011).

A documentação linguística abrange questões culturais e costumes tradicionais de um determinado povo, pois registra sua prática e o funcionamento da língua em diferentes contextos. De acordo com Himmelman (1998, p.167), a documentação linguística é multidisciplinar, porque auxilia diferentes estudos, como a sociologia, a antropologia, a análise do discurso, métodos de campo, corpus linguísticos, estudos educacionais, etc. O seu objeto, a "língua", engloba o conhecimento consciente e inconsciente, a idealização e habilidade cognitiva, como também o comportamento social evidente (WOODBURY, 2011).

Para Woodbury (2011), os registros devem basear-se em conceitos e técnicas linguísticas, etnográficas, psicológica, ciência computacional, arte, entre outras questões, para que, assim, as comunidades da fala e outras pessoas possam nutrir interesses, propósitos e aspirações para registro e documentação de língua. É importante que o público-alvo sejam os falantes daquela comunidade para que possam se sentir cada vez mais motivados em registrar sua língua, cultura e costumes tradicionais. No Brasil, cada vez mais, as comunidades estão procurando documentar os aspectos linguísticos e aqueles utilizados em diferentes práticas discursivas (ex. rituais, canções tradicionais, narrativas orais, etc.) com intuito de fortalecer a língua e a cultura.

De acordo com Schultze-Berndt (2016), o termo “documentação linguística” pode ser interpretado como um processo e um resultado. Na leitura dos resultados, a documentação de línguas é definida como um registro duradouro e polivalente, no sentido de um corpus abrangente de dados que podem ser utilizados pelas gerações posteriores que desejam explorar qualquer aspecto da língua pelo qual estão interessados, sejam eles linguísticos ou culturais. Em outras palavras, o resultado da documentação linguística é um registro acessível e de interesse de várias pessoas, sejam linguistas, antropólogos, historiadores, pesquisadores envolvidos na educação e no planejamento de revitalização das línguas e culturas e, claro, inclui-se, essencialmente, os membros da comunidade linguística e seus descendentes. Em casos mais extremos, um registro existente da língua pode formar a base para os esforços de revitalização, mesmo na ausência de falantes fluentes da língua (SCHULTZE-BERNDT, 2016). 
Desse modo, à medida que os projetos de documentação linguística são iniciados, registros e anotações sobre o seu progresso tornam-se disponíveis e seus resultados são depositados em arquivos de mídias (AUSTIN, 2010). Conforme Drude (2006), apesar da grande perda da diversidade linguística no mundo, a documentação linguística teve um grande avanço devido às novas tecnologias de documentação, como gravações de áudio e vídeos que possibilitaram realizar registros de alta qualidade em trabalhos de campo nas comunidades onde a língua é falada diariamente. Os programas computacionais especializados também auxiliam na criação de acervos digitais.

Em consonância com Himmelmann (2006, p. 1), a documentação linguística é "um registro duradouro e polivalente de um idioma”. Conforme esse autor, os dados primários que constituem a documentação de uma língua incluem gravações de áudios e vídeos de um evento comunicativo, elicitações ou transcrições. Esses dados primários devem ser organizados em um corpus estruturado e que possa ser acessível para vários tipos de anotações e comentários (HIMMELMANN, 2006).

No trabalho de campo é necessário manter o registro dos dados coletados em um arquivo digital com um corpus de gravação audiovisual da língua falada. Schultze-Berndt (2016) destaca que, além de um banco de dados lexicais, algumas variedades de materiais adicionais devem ser documentadas, como textos editados em formato imprimível, vídeos legendados, um esboço gramatical, fotografias e, o mais importante, informações sobre o conteúdo do arquivo e várias convenções adotadas em anotação. Tal arquivo idealmente estará em um formato e local que garanta tanto a longevidade, quanto a continuidade da acessibilidade às partes interessadas relevantes (SCHULTZE-BERNDT, 2016).

De acordo com Austin (2013, p.3), os linguistas chamaram a atenção para a necessidade urgente de registrar e analisar materiais linguísticos e o conhecimento linguístico dos falantes, enquanto esses idiomas (ou ameaças de registros e variedades especiais dentro deles) continuavam a ser falados, bem como, trabalhar com comunidades no apoio a idiomas ameaçados de extinção. Em consonância com Moore et al (2008, p.40), a situação das línguas no Brasil, onde muitas estão sob ameaças, torna-se preocupante e representativa no panorama mundial. Por isso, a documentação linguística é uma subárea essencial no desafio de documentar e descrever línguas em processos de obsolescência.

Um outro passo importante na documentação é a organização e preservação dos dados primários da língua registrada. Himmelmann (2006, p. 15) elenca cinco características fundamentais na documentação de uma língua: 
1. Focos nos dados primários - Documentação linguística se preocupa com a coleta e análise de uma matriz de dados linguísticos para que sejam disponibilizados para uma ampla gama de usuários;

2. Responsabilidade - Acessar os dados primários e suas representações realizando evoluçõos de análises linguísticas possíveis e esperadas;

3. Preocupação com o armazenamento a longo prazo e a preservação de dados primários - Documentação linguística inclui um foco no arquivamento, a fim de garantir que materiais documentais da língua sejam disponíveis para futuras gerações;

4. Trabalho interdisciplinar - A documentação requer informações e conhecimento de uma série de disciplinas e não se restringe à linguística;

5. Cooperação e envolvimento direto da comunidade da fala - A documentação requer um trabalho ativo e colaborativo com os membros da comunidade tanto como produtores de materiais da língua quanto co-pesquisadores.

Além desses passos importantes, Himmelman (2006, p.11) também chama atenção para os dados secundários, ou seja, os metadados, que devem conter as seguintes informações: (1) nomes dos participantes que estão sendo gravados; (2) quem fez os registros e para qual finalidade; (2) local e data do registro; (3) qual o equipamento se deve usar para determinados tipos de registros; (4) público-alvo e (5) uma breve caracterização do conteúdo que está sendo discutido e registrado. É importante mencionar que, além dos metadados, existe também os tipos de programas computacionais linguísticos que serão utilizados na edição, organização e análise dos conteúdos coletados em campo. Alguns programas que são bastante utilizados são: FLEX, Audacity, Transcriber, Elan, SayMore, WeSay ${ }^{6}$. Esses programas linguísticos e outros são ferramentas essenciais na análise e organização dos dados coletados.

Por fim, a documentação é um passo importante na revitalização de uma língua. Com esse estudo, é possível realizar decisões de planejamentos linguísticos, coletar dados para diferentes finalidades, elaborar materiais digitais como vídeos em formatos de DVD e/ou CDs de áudios, registrando alguma prática tradicional bastante importante para a comunidade. $\mathrm{O}$

\footnotetext{
${ }^{6} \mathrm{O}$ Flex é um programa que organiza dados lexicais e gramaticais dentro de um banco de dados; O Audacity auxilia nas edições das gravações que foram coletadas no trabalho de campo; Transcriber é um programa que transcreve foneticamente ou fonologicamente os áudios coletados; o ELAN é uma ferramenta utilizada para anotar e transcrever manual e semi-automaticamente, gravações de áudio ou vídeo; O WeSay é um programa para organização de dados lexicais na elaboração de dicionário e por fim o SayMore é uma plataforma que auxilia na organização dos dados coletados em campo. Com exceção do ELAN, Audacity e do Transcriber, os outros programas podem ser encontrados no site do SIL (https://www.sil.org/linguistics/linguistics-software).
} 
estudo também é a etapa inicial na análise de teorias linguísticas (fonética, fonologia, morfossintáticas, lexicais, semânticas, entre outras). Outro aspecto bastante importante no registro de uma língua é a descrição linguística, cujo objetivo é diferente da documentação, como mostraremos na subseção a seguir.

\subsection{O que é a descrição linguística?}

A descrição linguística se diferencia dos objetivos da documentação, no seu método de pesquisa, fluxos de trabalhos e resultados. Austin (2010) argumenta que muitos pesquisadores sugeriram que a documentação linguística é uma descrição, praticada por muitos estudiosos no início do século XX, com adição de tecnologias audiovisuais e gravação de vídeo. Para o autor (2010, p. 14), isso é "uma deturpação que falha no sentido da análise dos aspectos da documentação linguística que se diferenciam da descrição”. Himmelman (1998) explica que a documentação linguística se difere, fundamentalmente, da descrição linguística, pois essa última objetiva o registro de uma língua, sendo "língua" um sistema de objeto de elementos abstratos, construções e regras que constituem a estrutura subjacente invariante dos enunciados observáveis de uma comunidade da fala.

Para Austin (2010), a descrição linguística tipicamente objetiva a produção de gramática, dicionários e coleção de textos, cujo público-alvo é geralmente os linguistas ou estudiosos da área. A descrição linguística está mais preocupada em descrever fenômenos linguísticos encontrados nas línguas do mundo. Austin (2010) elucida que, embora a descrição baseie-se em um corpus, ela envolve uma análise de ordem diferente, ou seja, a descrição abrange uma compreensão da língua em um nível mais abstrato, como, por exemplo, um sistema de elementos, regras e construções fonológicas, morfossintáticas e semânticas. A descrição linguística, em geral, torna-se bastante útil para linguistas que se direcionam a trabalhar com gramática, estudos histórico-comparativos ou tipológicos.

Embora a descrição linguística tenha como público-alvo os linguistas, ela se torna importante também na elaboração de materiais didáticos e planejamentos educacionais. Com ela é possível desenvolver uma ortografia de uma língua (a partir dos estudos fonéticos e fonológicos), podemos elaborar uma gramática pedagógica (utilizando a morfologia e sintaxe da língua), dicionários (a partir dos léxicos coletados) e coletânea de textos. Assim, a descrição linguística e também a documentação são atividades que se tornam fundamentais nos planejamentos linguísticos de fortalecimento e revitalização de línguas. A subseção 
seguinte exibe alguns programas de documentação e descrição linguísticas que auxiliam no fortalecimento e revitalização de línguas minoritárias.

\subsection{Programas de documentação linguística no fortalecimento e revitalização de línguas}

Nessa subseção, exibiremos dois programas de documentação linguística (um de âmbito internacional e outro nacional) que auxiliam na preservação e políticas de fortalecimento linguísticos e culturais de línguas ameaçadas. O primeiro dele é o ELDP Endangered Languages Documentation Programme, da SOAS (University of London), da Inglaterra e o outro é o PRODOCLIN (Projeto de Documentação de Línguas Indígenas), no Museu do Índio, Rio de Janeiro, Brasil. Esses dois programas financiam projetos que têm como objetivo a documentação de línguas ameaçadas de extinção.

De acordo com as informações do site ${ }^{7}$ do ELDP, esse programa foi fundado em 2002, como parte de um projeto da Hans Rausing Endangered Language Project (HRELP). O programa tem como foco a preservação de idiomas ameaçados globalmente. Desse modo, os responsáveis desse programa se preocupam em documentar e preservar tais idiomas, financiando pesquisadores de todo o mundo para realizar trabalhos de campo e arquivar suas coletas de dados e disponibilizá-las gratuitamente.

Além disso, o ELDP realiza treinamentos anualmente para os seus beneficiários, assim como, treinamentos de técnicas de trabalho de campo e documentação para pesquisadores/acadêmicos que se interessam em trabalhos de documentação de línguas ameaçadas. Em 2019, a pesquisadora Dr. Mandana Seyfeddinipur que atualmente é a coordenadora do ELDP, ministrou dois cursos intensivos de técnicas de documentação linguística no Brasil, em duas universidades: Universidade de São Paulo (USP/SP) e a Universidade Federal do Pará (UFPA/PA). Esses cursos foram destinados aos alunos que trabalham com línguas indígenas, africanas e de sinais e teve como público-alvo linguistas.

O trabalho de treinamento, além do financiamento e divulgação, faz com que o ELDP crie uma rede mundial de especialistas que continuem seus trabalhos com línguas ameaçadas, ensinando novas gerações de pesquisadores as técnicas de trabalho de campo, de gravação, treinamento de programas linguísticos para organização dos dados e questões de ética. No Brasil, o ELDP já financiou até o momento 27 projetos de pesquisadores que se destinaram a

\footnotetext{
${ }^{7}$ Disponível em: https://www.eldp.net/en/about+us/
} 
documentar e descrever línguas originárias desse país, como podemos observar na tabela 1 abaixo.

Tabela 1 - Projetos de documentação de línguas brasileiras financiadas pelo ELDP

\begin{tabular}{|c|c|c|c|}
\hline & Línguas & Projetos & Pesquisadores \\
\hline 1 & Akuntsú & Documentation of Akuntsu & Aragon \\
\hline \multirow[t]{3}{*}{2} & Apurinã & Description and Documentation of the & Facundes \\
\hline & & Apurinã (Arawak) Language of Brazil: & \\
\hline & & Grammar, Dictionary and Text Collection & \\
\hline \multirow[t]{2}{*}{3} & Ayury & Documentation of Urgently Endangered & Moore \\
\hline & & Tupian Languages & \\
\hline \multirow[t]{2}{*}{4} & Desano & Deposit & Silva \\
\hline & & Desano - audio and video materials & \\
\hline \multirow[t]{2}{*}{5} & Dâw & Documentation of Dâw, a Naduhup language & Epps \\
\hline & & of Brazil & \\
\hline \multirow[t]{2}{*}{6} & Enawene Nawe & Language Documentation of Enawene-Nawe & Brandão \\
\hline & & (Arawak) & \\
\hline \multirow[t]{3}{*}{7} & Gavião & Documentation of Gavião and Suruí & Meyer \\
\hline & & Languages in whistled and instrumental & \\
\hline & & speech & \\
\hline \multirow[t]{3}{*}{8} & Gavião de Rondônia & Language documentation with a focus on & Moore \\
\hline & & traditional culture among the Gavião and & \\
\hline & & Suruí of Rondônia & \\
\hline 9 & Haliti & Verbal events in Paresi-Haliti & da Silva \\
\hline \multirow[t]{2}{*}{10} & Irãntxe-Myky & Documenting Iranxe-Manoki, an isolate of & Bardagil-Mas \\
\hline & & Brazilian Amazonia & \\
\hline 11 & Kanamari & Documentation of Kanamari & Stefan Dienst \\
\hline 12 & Karo & Documentation and description of Karo & Gabas Jr. \\
\hline \multirow[t]{2}{*}{13} & Kubeo & The work of the Kubeo Language & Chacon \\
\hline & & Documentation Team & \\
\hline 14 & Kotira & Kotiria Linguistic and Cultural Archive & Stenzel \\
\hline \multirow[t]{2}{*}{15} & Mekens & Documentation of Urgently Endangered & Moore \\
\hline & & Tupian Languages & \\
\hline \multirow[t]{2}{*}{16} & Mondé & Documentation of Urgently Endangered & Moore \\
\hline & & Tupian Languages & \\
\hline 17 & Oro Win & Documentation of the Oro Win language & Birchall \\
\hline
\end{tabular}




\begin{tabular}{|c|c|c|c|}
\hline 18 & Palikur & Documentation of the Palikur (Arawak) & Barros da Silva \\
\hline & \multicolumn{3}{|c|}{ Language } \\
\hline 19 & Panará & A Digital Documentation of Panará & Bardagil Mas \\
\hline \multirow[t]{2}{*}{20} & Paresí & Documentation and description of Paresi- & Brandão \\
\hline & \multicolumn{3}{|c|}{ Haliti (Arawak) } \\
\hline \multirow[t]{2}{*}{21} & Puruborá & Documentation of Urgently Endangered & Moore \\
\hline & \multicolumn{3}{|c|}{ Tupian Language } \\
\hline \multirow[t]{3}{*}{22} & Suruí & Documentation of Gavião and Suruí & \multirow[t]{3}{*}{ Meyer } \\
\hline & & Languages in whistled and instrumental & \\
\hline & & speech & \\
\hline \multirow[t]{3}{*}{23} & Suruí de Rondônia & Language documentation with a focus on & \multirow[t]{3}{*}{ Moore } \\
\hline & & traditional culture among the Gavião and & \\
\hline & \multicolumn{2}{|r|}{ Suruí of Rondônia } & \\
\hline 24 & Tuyuka & Documentation of Brazilian Tuyuka, Brazil & Vlcek \\
\hline 25 & Wa'ikhana & Wa'ikhana Linguistic and Cultural Archive & Stenzel \\
\hline \multirow[t]{2}{*}{26} & Хурауа & Documentation of Urgently Endangered & Moore \\
\hline & \multicolumn{3}{|c|}{ Tupian Languages } \\
\hline \multirow[t]{3}{*}{27} & Yanomama & Documentation and Description of the & \multirow[t]{3}{*}{ Ferreira } \\
\hline & & Yanomama of Papiu, an Endangered & \\
\hline & & Yanomami language of Brazil & \\
\hline
\end{tabular}

Fonte: Site do ELDP (https://elar.soas.ac.uk/)

No que diz respeito ao PRODCLIN $^{8}$ (Programa de Documentação de Línguas Indígenas), foi um programa criado em 2009 pela Fundação Nacional do Índio (FUNAI), Fundação Banco do Brasil e Unesco, por intermédio do Museu do Índio. Esse projeto visa a preservação do patrimônio cultural e linguístico dos povos indígenas brasileiros e promove o acesso cultural e linguístico para futuras gerações desses povos e também para pesquisadores interessados em trabalhar com documentação e descrição das línguas indígenas brasileiras.

Assim como ELDP, o propósito desse programa é documentar aspectos de línguas e culturais de povos indígenas em situação de alta vulnerabilidade e salvaguardar registros linguísticos e culturais para futuras gerações. O programa também oferece treinamento em pesquisas e documentação para pesquisadores indígenas, constitui um acervo digital público e de qualidade das línguas documentadas.

\footnotetext{
${ }^{8}$ Disponível em: http://prodoclin.museudoindio.gov.br/
} 
De acordo com as informações do site do PRODCLIN, 13 línguas indígenas já tiveram projetos de documentação financiados pelo programa, as línguas escolhidas se devem pelo critério de graus de ameaça, são elas: Apiaká, Desano, Haliti-Paresí, Kaiabi-Kawaiwete, Kanoé, Kisêdjê, Karajá, Maxakali, Ikpeng, Ninam, Rikbaktsa, Shawãdawa e Yawanawa.

Em suma, é possível compreender que, apesar da situação extremamente preocupante das línguas indígenas brasileiras, nos últimos anos, muitos pesquisadores têm se dedicado profundamente em documentar e descrever essas línguas, como meio de fortalecimento e revitalização. A seção que segue trata sobre isso.

\section{Modos de revitalização linguística e cultural}

Primeiramente, antes de se entrar na discussão sobre metodologias de revitalização linguística, faz-se necessário compreender como a participação das comunidades indígenas no registro e pesquisa de suas línguas tem ocorrido ao longo dos anos:

Desde os primeiros anos da conquista da América pelos europeus, a documentação e o registro de línguas indígenas ocorre basicamente segundo um dos seguintes padrões:

(1) o registro utilitário (missionário e colonialista);

(2) o registro "arqueológico" (naturalista, científico e colonialista);

(3) o registro fragmentado em proveito de teorias linguísticas.

Tais registros também se distinguem por orientar-se em uma das seguintes perspectivas:

(A) o registro culturalmente informado;

(B) o registro formal desenraizado da cultura (D’ANGELIS, 2016, p. 64).

D’Angelis (2016) relata que somente na década de 1960 e 1970 é que surgem os primeiros questionamentos sobre a perspectiva que faz, dos grupos sociais e suas comunidades, meros objetos de estudo e alvos de ações de intervenção. No entanto, as metodologias conhecidas como "pesquisa participante" e "pesquisa-ação" que surgem nesse período e são baseadas nas necessidades de grupos sociais, politicamente marginalizados, que têm como objetivo trocar informações para colaborar na mudança das condições de dominação da comunidade, apesar de ganhar espaço entre sociólogos e educadores, não alcançaram tão cedo a Linguística na América Latina, salvo raras exceções, a partir dos anos 80 (D’ANGELIS, 2016):

Os manuais clássicos de "pesquisa de campo" (como Samarin, 1967) forjaram a prática de pesquisa das primeiras gerações de estudiosos brasileiros de línguas indígenas, a partir da formação de linguistas (no país ou no exterior) de meados da década de 1970 em diante (D’ANGELIS, 2016, p. 69). 
A partir dos anos 1990, a pesquisa colaborativa (ou "pesquisa baseada na comunidade") começa a conquistar seu espaço entre as formas de se fazer pesquisa linguística. Esse tipo de pesquisa tem como objetivo uma investigação feita junto com a comunidade, por demanda dela própria, ou com a negociação dos tópicos de estudos em conjunto com ela. Trata-se de uma pesquisa, cujo escopo foi definido pela própria comunidade que demandou apoio de um linguista ou uma pesquisa proposta por um linguista, cujo foco e abrangência são negociados com a comunidade envolvida (D’ANGELIS, 2016).

O diferencial em relação à pesquisa colaborativa é que a comunidade se encontra envolvida e interessada nos resultados da pesquisa, de modo que ela acompanha e participa com interesse de todas as etapas de investigação. D’Angelis (2016) explica a importância desse diferencial para os resultados da pesquisa:

\begin{abstract}
Em uma pesquisa que não atende a interesses da comunidade e na qual seus membros participam apenas como "informantes" (isto é, prestadores de serviço ao pesquisador linguista), mesmo quando os "informantes" chegam a entender —ou talvez, e melhor dizer, vislumbrar- por onde vão os interesses da investigação, eles não sentem qualquer compromisso com a pesquisa e com seus resultados acadêmicos. Ademais, mesmo quando vislumbram os objetivos da investigação, eles não os entendem claramente porque não foram chamados a participar de sua definição, além de desconhecer suas hipóteses de partida e o modo de funcionamento das ferramentas de pesquisa. Dito de outro modo, na pesquisa colaborativa a comunidade envolvida tem participação na definição da pesquisa (seu foco, sua abrangência, seus limites), aporta conhecimento e amplia seu conhecimento com ela. Ocorre aí um processo de socialização e democratização de conhecimento (D'ANGELIS, 2016, p. 70).
\end{abstract}

Além disso, a presença de pesquisadores indígenas qualifica e evidencia diferentes matizes que, na maioria dos casos, são imperceptíveis para quem não pertence ao povo estudado. Por isso, é necessário que haja uma colaboração bilateral entre os pesquisadores não-indígenas e os membros da comunidade para que, em um trabalho colaborativo, a comunidade juntamente com os linguistas e demais pesquisadores possam encontrar uma solução que contemplem as necessidades de cada povo em relação a revitalização de suas línguas e culturas.

Feitas as considerações necessárias para a compreensão de uma metodologia de pesquisa colaborativa, pode-se pensar em quais ferramentas estão sendo utilizadas para a revitalização linguística das línguas brasileiras e quais ainda podem ser mais bem exploradas.

Franchetto \& Maia (2017) relatam uma experiência vivida no Brasil, entre 2001 e 2007, nos primeiros anos do curso de Licenciatura Indígena da Universidade Estadual de Mato Grosso, quando uma equipe de linguistas atuou como formadores de professores 
pesquisadores de mais de trinta etnias, falantes de cerca de trinta línguas, através de um ensino dinâmico e interativo dos fundamentos da Linguística. De acordo com a autora, diversos trabalhos de fim de curso da primeira turma de formados revelaram descobertas e o entusiasmo dos alunos, que, pela primeira vez, encontraram a fonética, a fonologia, a morfologia e a sintaxe no estudo de suas línguas, bem como, a complexidade das artes verbais indígenas (FRANCHETTO \& MAIA, 2017).

Frachetto \& Maia (2017) também citam o projeto desenvolvido na fronteira entre Brasil e Guiana Francesa, no qual um pequeno grupo de quatro jovens linguistas buscava renovar fundamentos, métodos e práticas da formação de professores indígenas. Trata-se do curso de Licenciatura Indígena do campus binacional do Oiapoque, Universidade Federal do Amapá. Dentre as etnias e línguas contempladas no curso, os autores ressaltam a presença das línguas Palikur, Karipuna e Galibi-Marworno e os projetos que afetam positivamente sua autoestima linguística, étnica e cultural (FRANCHETTO \& MAIA, 2017).

De acordo com Horst et. al (2017), não existem manutenção, promoção ou revitalização linguística sem que exista a consciência por parte do falante do valor dessa língua e da importância dessa ação. Os autores também ressaltam que a implementação de ações de conscientização linguística se dá através da circulação do conhecimento e das diferentes vozes presentes na comunidade e, no caso de línguas minorizadas, especialmente, as línguas indígenas, há ainda a necessidade de estabelecer um espaço de escrituralidade. Essa situação aumenta a relevância de projetos que fortaleçam a funcionalidade oral e escrita dessas línguas e que desenvolvam as habilidades orais e escritas dos falantes (HORST et. al, 2017).

O Programa de Revitalização de Línguas Indígenas no Estado de São Paulo, iniciado em 2013, em uma parceria da Organização Não Governamental KAMURI com a FUNAI (Coordenação Regional Litoral Sudeste) e com o Grupo de Pesquisas InDIOMAS, da UNICAMP é também um exemplo de pesquisa colaborativa que visa promover a revitalização linguística e cultural de povos indígenas brasileiros. Por meio do programa, foram realizadas oficinas de revitalização linguística com os Nhandewa-Guarani, com os Kaingang Paulistas e com os Krenak no Oeste Paulista.

Alguns dos resultados do Programa de Revitalização de Línguas Indígenas no Estado de São Paulo são a publicação do primeiro Dicionário Escolar do Kaingâk Paulista, uma publicação de cerca de 300 páginas, com cerca de 3 mil entradas, e perto de 200 imagens e de duas obras importantes para os Krenak: um Vocabulário Unificado Krenak (Botocudo) que reúne os três principais vocabulários dessa língua registrados no século XIX, e um texto 
etnográfico sobre os "Botocudos do Leste do Brasil", escrito por Curt Nimuendajú (traduzido da publicação em inglês, de 1946).

O programa prevê também o lançamento de Lições de Gramática Nhandewa/TupiGuarani vol. 2 -Caderno de Atividades Multidisciplinares e, junto com ele, um livro de textos de leitura. O primeiro volume de Lições de Gramática Nhandewa-Guarani - vol. I já foi publicado, assim como, o livro Inypyrũ - Narrativa sagrada da criação do mundo, ambos produzidos ao longo das oficinas do projeto de revitalização do Nhandewa-Guarani na Aldeia Nimuendajú. $\mathrm{Na}$ promoção de uma língua de existência essencialmente oral, cresce o significado de práticas de uso escrito, e projetos de revitalização linguística carecem muitas vezes de materiais que ainda precisam ser escritos.

\subsection{Um exemplo de revitalização linguística: línguas indígenas no meio digital}

A realidade das línguas indígenas é outra hoje. A população indígena urbana é um fenômeno real, atual e em pleno crescimento. Na situação em que as línguas indígenas se encontram, principalmente, as que estão em processo de perda de transmissão intergeracional, é essencial o fortalecimento da oralidade por meio de projetos que utilizem as mídias digitais. É importante que haja a criação e divulgação de conteúdos interativos em línguas indígenas que podem ter um viés educativo, trazer elementos da cultura e das línguas de cada comunidade. A participação dos falantes na criação desses conteúdos constitui um critério importante para construir a imagem social da língua.

O Projeto Web Indígena9, cuja realização aconteceu em parceria com a ONG KAMURI e com apoio institucional e também financeiro da Pró-Reitoria de Extensão e Assuntos Comunitários (PREAC) da Unicamp, foi responsável pela criação e manutenção de 3 sites de etnias indígenas (Kaingang, Nhandewa-Guarani e Xokleng/Laklãnõ), sendo que o site "Kanhgág Jógo" (www.kanhgag.org), lançado em dezembro de 2008, é o primeiro site totalmente em língua indígena no Brasil. Para o desenvolvimento desses sites, foram realizadas diversas oficinas, nas quais a participação e atuação dos membros de cada comunidade foram essenciais. A atuação da comunidade é essencial, uma vez que o povo é detentor do conhecimento que deve ser explorado e divulgado nos sites e são eles os maiores interessados em dar continuidade à manutenção dos conteúdos nesse meio digital.

No entanto, a mídia representa um recurso tecnológico ainda subaproveitado em ações de promoção e conscientização linguística, seja porque se orienta pelas "leis do mercado",

\footnotetext{
${ }^{9}$ Disponível em: http://www.webindigena.org/
} 
seja porque sua execução exige um aparato específico (HORST et al, 2017). Horst et al (2017) relatam o impacto social de um programa de rádio em uma língua minoritária na região Oeste de Santa Catarina: “Os falantes são ouvintes assíduos e regulares. Além disso, a internet, veículo prático e atual de disseminação de informações, é outro meio no qual vídeos e curta metragens em língua minoritária podem ser circulados (HORST et al, 2017, p. 13).

Uma nova ferramenta para o fortalecimento linguístico e para a revitalização linguística e cultural é a criação de jogos digitais. Um exemplo disso é o jogo Huni Kuin, desenvolvido a fim de abordar a cultura do povo indígena Kaxinawá (ou Huni Kuin, como os próprios se denominam), com o objetivo de possibilitar uma experiência de intercâmbio de conhecimentos e memórias indígenas por meio da linguagem dos videogames:

\begin{abstract}
A produção do jogo foi uma criação coletiva da equipe de pesquisadores e técnicos nawá (não indígenas) e dos Huni Kuin envolvidos no projeto, que buscaram um esforço permanente de tradução entre culturas, mídias e formatos. Desse modo, foram percorridos trajetos que vão dos mitos e histórias aos roteiros das fases, dos grafismos huni kuĩ à arte digital, dos cantos aos desenhos e às animações, da cosmologia às mecânicas de jogo $\mathrm{e}$ às diferentes formas de jogabilidade (MENESES, 2017, p. 84).
\end{abstract}

Um outro exemplo de jogo desenvolvido em colaboração entre pesquisadores, equipe técnica e uma comunidade indígena é o jogo Never Alone, sobre o povo Iñupiaq (nativos que habitam o Alasca desde a pré-história). O jogo foi desenvolvido em uma parceria entre um estúdio e mais de 40 nativos do Alasca que não apenas contaram suas histórias para colaborar com o enredo, mas também participaram na criação de ilustrações e design.

Inspirados por essas iniciativas e por acreditar que jogos são sistemas poderosos de aprendizado que possibilitam a exploração de limites e possibilidades, estimulando a ação colaborativa entre os jogadores, uma equipe formada por linguistas, programadores e artistas visuais propôs a criação de um jogo eletrônico para a comunidade Guarani Nhandewa, da Terra Indígena Piaçaguera (Litoral Sudeste). O projeto tem como objetivo o desenvolvimento de um jogo digital educativo e interativo que aborda aspectos da cultura e da língua dos Guarani Nhandewa. Este projeto faz parte de uma série de projetos de revitalização linguística em parceria com o Grupo de Pesquisas InDIOMAS (UNICAMP), a ONG Kamuri e a FUNAI (Litoral Sudeste). A criação do jogo Guarani Nhandewa busca desenvolver uma estratégia de aprendizado interativa sobre aspectos culturais e linguísticos que está sendo planejada juntamente com a comunidade Guarani Nhandewa para que, por meio de um jogo digital, as crianças da comunidade possam revisitar aspectos importantes relacionados à ancestralidade e 
ao modo de pensar de sua comunidade, ao mesmo tempo, que se identifiquem com o meio ambiente e as ações propostas pelo jogo.

Sendo assim, percebe-se a importância da presença de uma equipe interdisciplinar em projetos de revitalização linguística, uma vez que a equipe de desenvolvimento dos jogos eletrônicos é formada não apenas por linguistas, mas também por artistas visuais e profissionais da área de computação. Finalmente, reforça-se que a participação dos próprios membros da comunidade indígena é fundamental, pois somente por meio de um trabalho colaborativo com a comunidade, é possível desenvolver uma solução que contemple as necessidades de cada povo em relação à revitalização de suas línguas e culturas.

\section{Considerações finais}

O artigo apresentou alguns aspectos importantes a respeito do fortalecimento, conhecimento e revitalização de línguas ameaçadas de extinção. Observou-se que a documentação e a descrição linguística são etapas essenciais na revitalização e/ou manutenção de uma língua. E que o fortalecimento desse elo entre documentação e descrição é fundamental para qualquer êxito no processo de revitalização de uma língua.

Os Arquivos Digitais que documentam os registros de trabalhos realizados em comunidades indígenas auxiliam na preservação e valorização do patrimônio cultural e linguístico existente no Brasil. Consequentemente, essa documentação também contribui para trabalhos descritivos que auxiliam na elaboração de gramáticas, dicionários, textos e a circulação do conhecimento científico delas. Verificamos que programas de documentação linguística são essenciais no financiamento de projetos que visam à documentação, descrição, fortalecimento e revitalização de línguas ameaçadas.

É importante mencionar a necessidade de profissionais capacitados para trabalhar na descrição e documentação dessas línguas. Desse modo, compreendemos que a valorização das línguas indígenas é fundamental para a humanidade em geral. O ano de 2019 foi dedicado às línguas indígenas (International Year of Indigenous languages - IYIL2019) pela UNESCO e, espera-se que, a partir das políticas linguísticas e públicas, a favor dos povos indígenas seja possível cada vez mais reafirmar a luta contra a perda da diversidade linguística, uma vez que todas as 150 línguas permanecendo vivas no território brasileiro, estão em constante ameaças de extinção.

Por fim, reafirmamos que tanto os trabalhos de descrição e documentação, quanto as ações de revitalização linguística podem se beneficiar muito da presença de equipes 
multidisciplinares e dos conhecimentos e participação dos membros das comunidades indígenas, pois se considerarmos as dificuldades e riscos que as línguas indígenas brasileiras estão enfrentando, é fundamental que novas metodologias e parcerias surjam, com o objetivo de fortalecimento dessas línguas e culturas que apresentam formas únicas de ver e compreender o mundo, e que não devem desaparecer.

\section{Referências bibliográficas}

AUSTIN, Peter. Current Issues in languages documentation. Language Documentation and Descripition, Londres: SOS, v. 7, p.12-33, 2010.

AUSTIN, Peter; SALLABANK, Julia. Language endangerment. Cambridge University Press, New York, 2011, $581 \mathrm{p}$.

CRYSTAL, David. A revolução da linguagem. Tradução Ricardo Quintana. Rio de Janeiro: Jorge Zahar Editores, 2005.

D’ANGELIS, Wilmar da Rocha. Kaingáng: questões de língua e identidade. (1996). Liames: Línguas Indígenas Americanas, v. 2, Campinas: IEL-Unicamp, p. 105-128, 2002.

Quando os falantes nativos são os professores, os professores são pesquisadores, e os linguistas são parceiros. Signo y Seña, v. 29, Buenos Aires: Facultad de Filosofia y Letras (UBA), p. 63-77, 2016.

. Línguas Indígenas no Brasil: quantas eram? Quantas são? Quantas serão? Revitalização de Línguas Indígenas: como fazemos. Campinas-SP: Curt Nimuendajú: Kamauri, 2019, p.13-27.

DRUDE, Sebastian. Documentação Linguística: O Formato de Anotações de Textos. Estudos Linguísticos, XXXV, p.27-51, 2006.

FERREIRA DA COSTA, Francisco Vanderlei. Revitalização e ensino de língua indígena: interação entre sociedade e gramática. Tese (Doutorado em Ciências e Letras) - UNESP, Araraquara (SP), 2013.

FRANCHETTO, Bruna; MAIA, Marcus. Educação e Revitalização linguísticas. (2017). Revista LinguíStica: Revista do Programa de Pós-Graduação em Linguística da Universidade Federal do Rio de Janeiro, v. 13, Rio de Janeiro: Universidade Federal do Rio de Janeiro, p. 1-10.

GALUCIO, Ana Vilacy; MOORE, Denny; VOORT, van der Hien. O patrimônio linguístico do Brasil: novas perspectivas e abordagens no planejamento e gestão de uma política da diversidade linguística. Revista patrimônio histórico e artístico nacional, IPHAN, n. 38, 2018, p.195-218.

HALL Jr., Robert A. The life-cycle of pidgin languages. Lingua, 78, 1962, p. 152-155. 
HIMMELMANN, Nikolaus P. Documentary and descriptive linguistics. Linguistics. 1998, 36:161-95.

Language Documentation: What is it and what is it good for? In: GIPPERT, Jin; HIMMELMAN, Nikolaus; MOSEL, Ulrike (Org.). Essentials of Languages Documentation. Berlim: Mouton de Gruyter, 2006, 437 p.

HORST, Cristiane; KRUG, Marcelo Jacó; FORNARA, Ana Elizabeth. Estratégias de manutenção e revitalização linguística no oeste catarinense. Organon: Revista do Instituto de Letras da UFGRS, v. 32, Porto Alegre: Universidade Federal do Rio Grande do Sul, p. 1-16, 2017.

MOORE, Denny, GALUCIO, Ana Vilacy, GABAS JUNIOR, N. Desafio de documentar e preservar línguas. Scientific American Brasil. v.3, p. 36 - 43, 2008. Edição Especial.

MOORE, Denny; GALUCIO, Ana Vilacy. Perspectives for the documentation of indigenous language in Brazil. In: Gabriela Pérez Báez; Chris Rogers; Jorge Emilio Rosés Labrada (Org.). Language Documentation and Revitalization in Latin American Contexts. 1 ed. Berlin: De Gruyter, v. 295, p. 29-58, 2016.

MENESES, Guilherme Pinho. Saberes em jogo: a criação do videogame Huni Kuin: Yube Baitana. GIS: Gesto, Imagem e Som, v. 2, São Paulo: Universidade Estadual de São Paulo, p. 83-110, 2017.

MOSELEY, Christopher (ed.). Atlas of the World's Languages in Danger, 3rd edn. Paris, 2010. UNESCO Publishing. Online version: http://www.unesco.org/culture/en/endangeredlanguages/atlas.

RODRIGUES, Aryon. Línguas Indígenas: para o conhecimento das línguas indígenas. São Paulo: Loyola, 1986. 1993.

Línguas indígenas: 500 anos de descobertas e perdas. D.E.L.T.A., v. 9, n.1, p. 83-103,

Sobre as Línguas Indígenas e sua pesquisa no Brasil. Linguas do Brasil/Artigos, p.35-38, 2005.

RODRIGUES, Ulisdete Rodrigues de Souza. Elementos para a compreensão de Línguas Crioulas e Pidgins: conceitos e hipóteses. Abe África: revista da associação brasileira de estudos africanos, v.02, n.02, p. 43 - 59, 2019.

SCHULTZE-BERNDT, Eva. Language Documentation. Syntax-theory and analysis. An international handbook. ed. / Tibor Kiss; Artemis Alexiadou, v. 3, Berlin: de Gruyter, Walter GmbH \& Co, 2015. p. 2063-2094.

SEKI, Lucy. Línguas Indígenas do Brasil no Limiar do século XXI. Impulso, Piracicaba, v. 12, n. 27, p. 157-170, 2000. 
WOODBURY, A. C. Language Documentation. In: AUSTIN, P. K.; SALLABANK, J. (Org.). Language documentation and archiving. New York: Cambridge University Press, 2011. p. 159-186. DOI https://doi.org/10.1017/cbo9780511975981.009.

Submetido em 05 de janeiro de 2021. Aceito em 24 de abril de 2021.

Publicado em 01 de junho de 2021. 